\title{
Preservation of bamboos using pressurized bamboo treatment unit
}

\author{
S.P. KURHEKAR, S.K. JAIN AND P.P. CHAVAN
}

\begin{abstract}
Bamboo is a woody, valuable, strong and exceptionally fast growing grass. Bamboos are mostly used for structural purposes in rural and tribal housing. But the presence of large amount of starch makes bamboo highly susceptible to attack by staining fungi and powder-post beetles. It deteriorates in a couple of years, putting heavy pressure on the resource, owing to increased demands for frequent replacements. This adversely affects the supplies of bamboo, even in bamboo rich regions. Preservation can extend the life of bamboo and can maintain its quality and hence, make it suitable for the use as construction material. Different preservation methods are used for this purpose. In present study, pressure treatment was developed for treating bamboo by using copper chrome boron, cashew nut shell liquid and cow urine. By using developed treatment unit bamboos can be treated within 2 hours. Tensile strength for Mes above soil was found to be $30.16 \mathrm{~N} / \mathrm{mm}^{2}, 29.40 \mathrm{~N} / \mathrm{mm}^{2} \mathrm{and} 26.94 \mathrm{~N} / \mathrm{mm}^{2}$ for CCA, CCB and untreated, respectively and compressive strength was found to be $13.06 \mathrm{~N} / \mathrm{mm}^{2}, 12.58 \mathrm{~N} / \mathrm{mm}^{2} \mathrm{and} 10.38 \mathrm{~N} / \mathrm{mm}^{2}$ for CCA, CCB and untreated, respectively after 90 days of environmental exposure. The tensile and compressive strength of chemically treated bamboos was found to be better than untreated bamboos.
\end{abstract}

KEY WORDS : Bamboo efficiency, Perservation of bamboos, Pressurized bamboo treatment unit, Strength of bamboo

How to cite this Article : Kurhekar, S.P., Jain, S.K. and Chavan, P.P. (2015). Preservation of bamboos using pressurized bamboo treatment unit. Engg. \& Tech. in India, 6 (1) : 25-28. 